\title{
Assessment of the effects of the inclusion of poor quality sediment samples on spatial predictions of seabed sediments in the Australian marine margin
}

\author{
$\underline{\text { B. Dunn }}^{\text {a }}$ and $\mathrm{J} . \mathrm{Li}^{\mathrm{a}}$ \\ ${ }^{a}$ Geoscience Australia, GPO Box 378, Canberra, ACT 2601, Australia \\ Email: bex.dunn@ga.gov.au
}

\begin{abstract}
Spatial predictions of seabed sediments based on samples in the Australian Marine Samples (MARS) database provide environmental baseline information used in the management of Australia's marine jurisdiction, offshore resource development, and marine protected areas. Interpolations of seabed samples are often required for understanding target regions between collection sites. Data quality in the MARS database varies, with data quality control resulting in the exclusion of over 7,000 samples, most of which were dredged samples. Dredged samples are thought to lower the accuracy of the spatial predictions produced from the database. In this study we examined whether these excluded dredged samples should be used for spatial predictions by assessing whether the dredged samples decreased or increased the accuracy of the resulting spatial predictions of seabed mud content, and whether the dredging method used altered the accuracy of the resulting prediction.
\end{abstract}

We confined our analyses to two contrasting areas in the Australian Exclusive Economic Zone (AEEZ): the Southwest Region (407 total samples; 150 dredged) and Petrel Region (534 total samples; 297 dredged). We compared the accuracy of interpolated surfaces of mud content generated from quality controlled (QCed) samples with surfaces generated with samples from different dredge types (benthic, pipe, chain bag and unspecified). In the Southwest region samples included 73 benthic, 19 pipe, 41 chain bag, and 17 unspecified dredged samples. In the Petrel region samples included 46 pipe and 251 unspecified dredged samples. Spatial predictions of seabed mud content were made using Inverse Distance Weighting (IDW) and Ordinary Kriging (OK). Predictive errors were assessed based on leave-one-out cross-validation in terms of relative mean absolute error (RMAE). The effects of the dredged samples on the predictive error were analysed using paired Mann-Whitney tests.

For sediment samples in the Southwest region, including benthic dredge samples in the prediction reduced the accuracy of IDW by $1.79 \%$ in terms of RMAE. Including chain bag dredge samples increased the accuracy of IDW with a small difference in RMAE of $0.47 \%$. The difference in accuracy of IDW was insignificant for the unspecified type samples, all dredged sample types and pipe dredged samples. Including samples with alldredged type and unspecified type dredge samples improved the accuracy of the OK predictions over the QCed samples in the Southwest region with a small effect on RMAE of $0.68 \%$ for all-dredged samples and $0.65 \%$ for unspecified type dredged samples. The difference in accuracy of OK was insignificant for benthic dredged, pipe dredged and chain bag dredged samples in the Southwest region. No significant effects on the accuracy of IDW in the Petrel region were found for all the tested dredged sample types (unspecified type, pipe dredged samples, and all-dredged samples). The difference in accuracy of OK in the Petrel Region for samples with all dredged and with unspecified dredged samples was insignificant. Including pipe dredged samples increased the accuracy of $\mathrm{OK}$ in the Petrel with a negligible effect on RMAE of $0.02 \%$.

In summary, the inclusion of dredged samples produced minimal effects on the accuracy of spatial predictive models. Effects were not consistent across region or dredge type, but findings showed dredged samples had surprisingly little effect on the accuracy of the predictions. Including the dredged samples would require reprocessing the spatial predictions for the AEEZ based on the MARS database, so as the findings are only based on mud sediment data from two regions, caution should be taken to generalise these findings to other sediment types and to the entire Australian marine margin. Further testing is required to verify these findings for other methods, regions and sediment types and identify whether future spatial predictions can include some of this extra data without a loss in accuracy.

Keywords: Spatial interpolation, inverse distance weighting, ordinary kriging, seabed sediment samples, dredge sampling types 
Dunn and Li, Assessment of the effects of the inclusion of poor quality sediment samples on spatial predictions of seabed sediments in the Australian marine margin

\section{INTRODUCTION}

Geoscience Australia produces continuous spatial products such as seabed sediment predictions based on the Marine Samples (MARS) database. Spatial predictions of seabed sediments provide environmental baseline information to support the management of the Australian Marine Jurisdiction (Passlow, 2005). These predictions are also valuable in sediment mobility and environmental modelling (Brodie et al., 2013), in offshore resource and engineering project planning (Porter-Smith et al., 2004) and in the management of marine protected areas (Falkner et al., 2009).

To improve the quality of the spatial predictions of seabed sediments, a number of studies have been completed. These studies include: 1) the effects of the spatial reference system used on the performance of the interpolator in the prediction of seabed mud and sand content (Jiang and Li, 2014; Turner, 2017), 2) the performance of various machine learning and geostatistical methods in the spatial prediction of seabed sediments, (Li et al., 2011; Li et al., 2010; Li et al., 2012), 3) the effects of secondary variables on the predictive errors (Li, 2013) and 4) the influence of the spatial distribution and density of samples on the resulting predictions in efforts to improve predictions (Li et al., 2011). Data quality control (QC) on the MARS database was implemented to ensure the quality of the spatial predictions, resulting in less than 7000 samples available for the Australian studies (Li et al., 2010; Li et al., 2012). The scarcity of these seabed sediment point samples is of international concern (Stephens and Diesing, 2015), with studies attempting to improve the spatial prediction of seabed sediment data by using empirical, site-specific models to improve predictions for local areas (Stephens and Diesing, 2015), and, in a similar method to this study, using geostatistical methods in reinterpreting legacy sediment data to produce maps of the probability that sediment classes are located around the UK continental shelf (Lark et al., 2012). In this study we attempted to improve the spatial predictive model accuracy by including previously excluded dredged samples. In this study, we aim to: 1) test the effects of the inclusion of previously excluded poor quality samples on the accuracy of spatial predictive models, 2) determine whether different dredge types have different effects on the accuracy of spatial predictions of seabed mud content in different regions, 3) assess whether the decision to discard dredged samples was valid, and 4) address whether we can improve future spatial predictions by including dredged samples, thus increasing the number of usable samples.

\section{METHOD}

\subsection{Study areas and datasets}

Two geographically distinct, distant regions of the Australian marine margin were chosen to analyse the effects of including previously discarded samples in the spatial predictions of seabed mud content to reduce the likelihood that results would be affected by regional peculiarities (Figure 1). The Southwest region covers $525,265.9 \mathrm{~km}^{2}$, with 257 QCed samples and a sample density of 0.5 samples per $1000 \mathrm{~km}^{2}$ (Li et al., 2012) . The Petrel region is located in the northwest of the AEEZ, covering 286,406 km², with 237 QCed samples and a sample density of 0.8 samples per $1000 \mathrm{~km}^{2}(\mathrm{Li}, 2013)$.

Maps of the MARS database are produced for publication using the inverse distance weighted interpolator (Passlow, 2005). Sand, mud and gravel content for samples in the MARS database is given as a percentage by weight of the total sample (Passlow, 2005). Mud content data was used in this study to assess the impact of including dredged samples in spatial predictions of seabed sediment as mud content in dredged samples was believed to be negatively affected by dredge construction and deployment (Li et al., 2010).

\subsection{Dataset quality control procedures}

Data QC procedures were developed for samples from the MARS database in a series of studies into the prediction of the spatial distribution of seabed sediments (Jiang and Li, 2014; Li et al., 2010; Li et al., 2012). These QC procedures for seabed mud data resulted in the removal of 7394 samples in line with QC criteria (Figure 2), detailed in Li et al. (2012). Of the removed samples, 3892 were dredged samples. Dredged samples were removed due to concerns including possible low positional accuracy. These concerns arose from the possibility of the transect over which the dredge was dragged by the ship ranging from a few hundred metres to over a kilometre in length (Li et al., 2012).

Sediment mixing during the sampling process may also occur in dredged samples (Li et al., 2010). As dredges are often deployed to sample rugged seafloor areas (Kidd et al., 1990), the removal of dredged samples from seabed sediment predictions may have reduced the distribution of gravel in seabed sediment maps by removing samples with higher gravel content. 
Dunn and Li, Assessment of the effects of the inclusion of poor quality sediment samples on spatial predictions of seabed sediments in the Australian marine margin

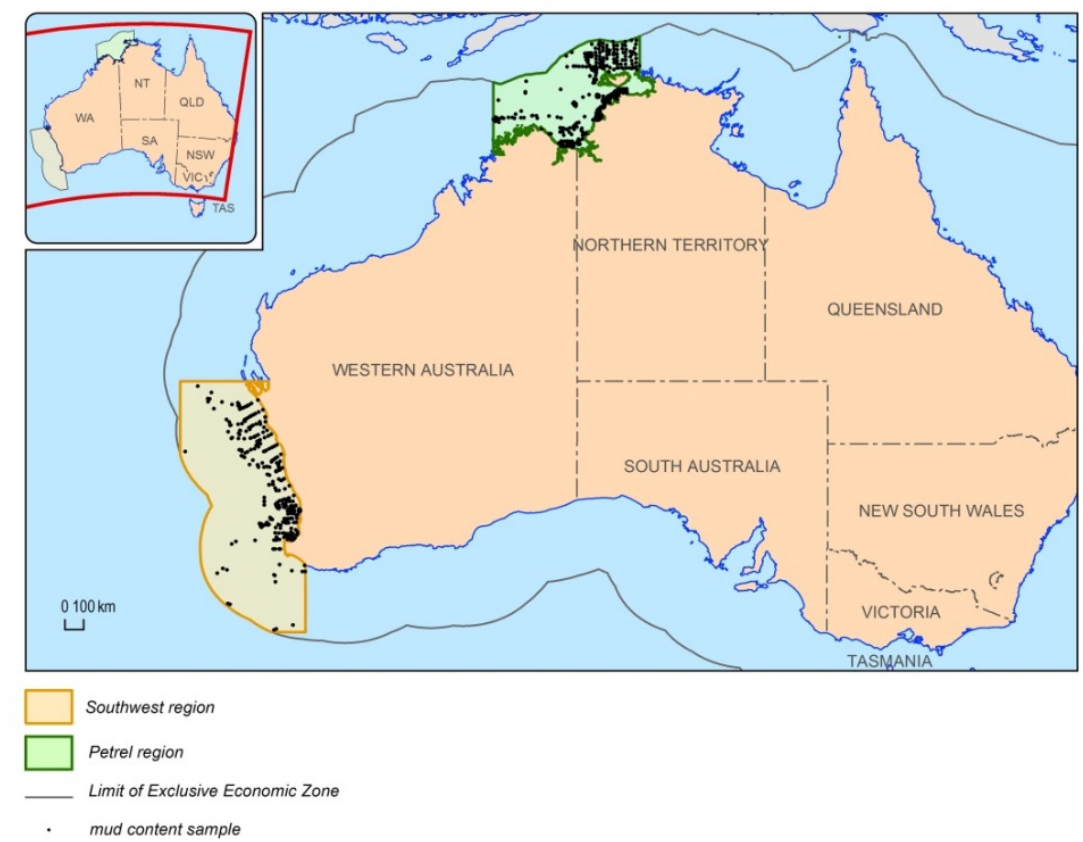

Figure 1. Map of Australian marine margin showing spatial distribution of mud content samples in extent of Petrel and Southwest study regions

Dredged samples in the MARS Database are separated into four categories: benthic, chain bag, pipe and 'unspecified'. Benthic type is defined as samples collected using benthic sleds which are designed to scrape along the sea floor, collecting material in a collecting bag. (Blomqvist and Lundgren, 1996). Doors at the rear retain material when the sled is retrieved (Heap et al., 2008).

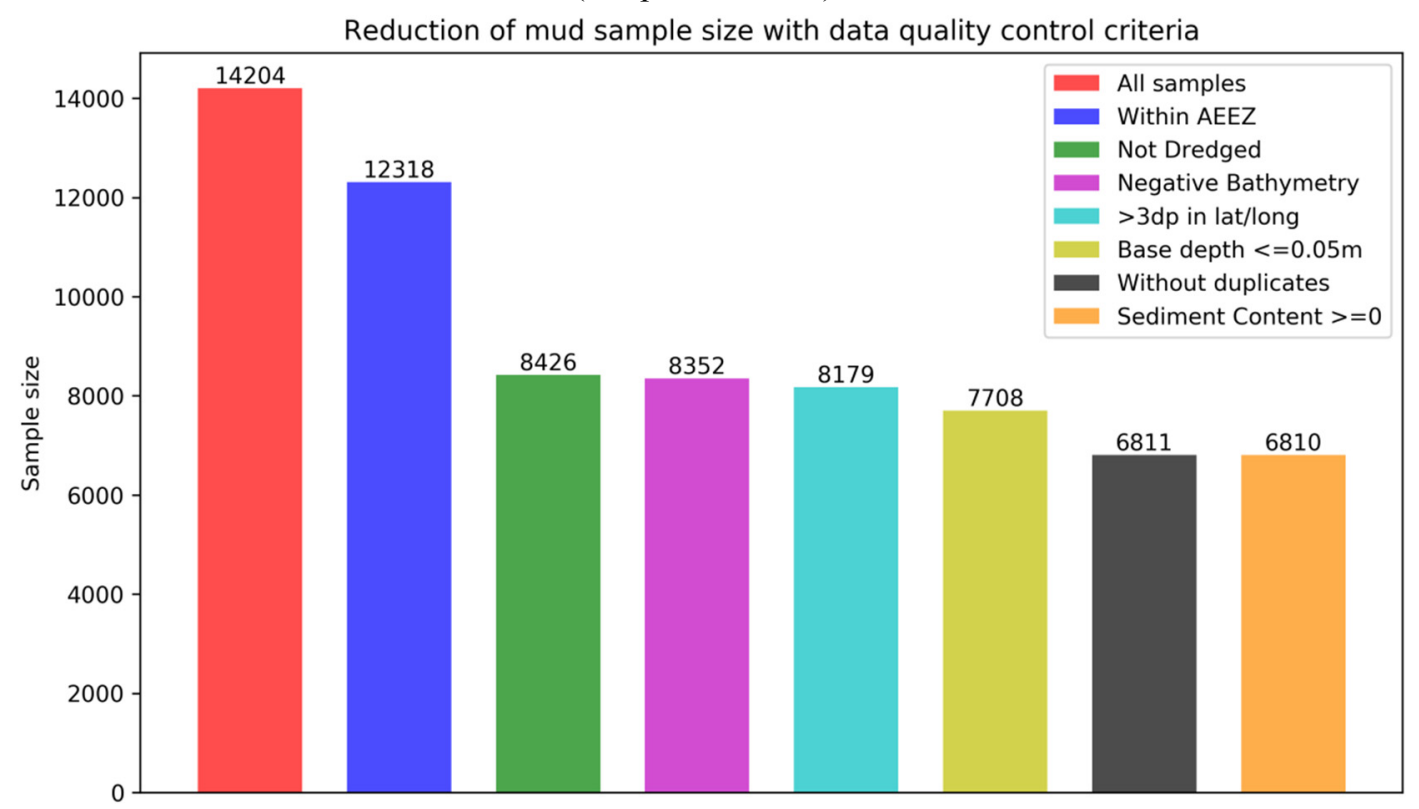

Figure 2. Change in sample size with application of QC criteria from Li et al. (2012)

Chain bag type is defined as samples collected using chain bag dredges. Chain bag dredges are a bag made of chain links, with a heavy metal collar to keep the mouth of the bag open (Heap et al., 2008). They are designed to collect rock samples in areas with rocky bottoms without snagging on the bottom (Kidd et al., 1990). The gauge of chain used in the chain bag affects the size of gravel and rock samples retained; smaller fractions of mud and sand may be lost, affecting the measurements of mud, sand and gravel in samples (Li et al., 2010). Chain bag dredges are sometimes used in conjunction with pipe dredges (Hailwood and Kidd, 2012), where the pipe dredges are used to collect finer material (Heap et al., 2008). Pipe type samples are defined as samples collected using pipe dredges. Pipe dredges consist of a pipe, generally around $15 \mathrm{~cm}$ diameter and $45 \mathrm{~cm} \mathrm{long}$, with a collecting bag (Hailwood and Kidd, 2012). Pipe dredges may be less likely to lose material than chain 
Dunn and Li, Assessment of the effects of the inclusion of poor quality sediment samples on spatial predictions of seabed sediments in the Australian marine margin

bag dredges, as the pipe is solid rather than made of chain. Dredged samples in the 'unspecified' category could belong to any of the dredge types above, but relevant information is missing in the MARS database.

\subsection{Spatial prediction and error measures}

Inverse Distance Weighting (IDW) and Ordinary Kriging (OK) methods were used in this study to compare the accuracy of interpolated surfaces of mud content. IDW and OK were chosen as IDW has been used in the past to produce maps from the MARS database, both IDW and OK have been used in other studies into improving the spatial seabed sediment predictions (Li et al., 2010) and they are the most commonly used methods for spatial predictions ( $\mathrm{Li}$ and Heap, 2008; Li et al., 2011). IDW and OK were implemented in the Geostatistical Analyst Extension, ArcGIS ArcMap 10.2 (ESRI, 2013). A power parameter of 2 and 12 neighbours were used with IDW as in previous studies (Li et al., 2012; Turner, 2017) on the MARS dataset. Following the method of Jiang and Li (2014) OK data was transformed using the arcsine square root transformation. A spherical variogram model with parameters optimised in ArcGIS used a weighted leastsquares algorithm to minimise the mean square error of the cross-validation output (ESRI, 2013). OK also used 12 neighbours. Leave-one-out cross validation was implemented in ArcGIS. Error estimates for each point were compared for the points included in each clean dataset. Four error measures were used to compare the accuracy of the original datasets and the datasets with the dredged samples: mean absolute error (MAE), root mean square error (RMSE), relative MAE (RMAE), Relative RMSE (RRMSE) and variance explained by predictive models based on cross-validation (VEcv) (Li, 2016; 2017; Li and Heap, 2008). Only the results of RMAE were reported in this paper due to space limitations; other measures are available in Dunn and Li (2018). Paired Mann-Whitney tests were used to compare the RMAE between predictions of seabed sediment distribution produced with and without including dredged samples. The paired Mann-Whitney tests were performed using the R statistical analysis software (R Development Core Team, 2016).

\section{RESULTS}

\subsection{Southwest region results - IDW}

The RMAE of IDW for the QCed samples in the Southwest region is $26.70 \%$ (Table 1). RMAE of IDW for samples with all the dredged samples (D-A) is $27.43 \%$ and RMAE of IDW for QCed samples with pipe dredged samples (PD) in the Southwest region is $26.82 \%$. Both D-A and PD have higher predictive error of IDW than the QCed samples. Mann-Whitney tests on IDW predictive errors for D-A and PD give p-values of 0.7295 and 0.9165 respectively (Table 1$)$, which are not significant.

Table 1. RMAE of IDW and OK for various sample types for the Southwest region and the differences (pvalues) in the RMAE between QCed samples (without dredge) and samples with various dredged samples based on paired Mann-Whitney tests.

\begin{tabular}{|l|l|l|l|l|l|}
\hline \multirow{2}{*}{ Sample type } & \multicolumn{2}{|c|}{ IDW } & \multicolumn{2}{c|}{ OK } & \multicolumn{1}{c|}{ p-value } \\
\cline { 2 - 6 } & RMAE (\%) & \multicolumn{1}{c|}{ p-value } & \multicolumn{1}{c|}{ RMAE (\%) } & \multicolumn{1}{c|}{$\mathrm{n}$} \\
\hline Without Dredge (QCed) & 26.70 & - & 28.30 & - & 257 \\
\hline Dredge - All (D-A) & 27.43 & 0.7295 & 27.62 & 0.0010 & 407 \\
\hline Benthic Dredge (BD) & 28.49 & 0.0478 & 32.61 & 0.1250 & 330 \\
\hline Pipe Dredge (PD) & 26.82 & 0.9165 & 29.53 & 0.4410 & 276 \\
\hline Chain Bag Dredge (CBD) & 26.23 & 0.0469 & 27.05 & 0.8074 & 298 \\
\hline Dredge - Unspecified (D-U) & 26.64 & 0.1861 & 27.65 & 0.0000 & 274 \\
\hline
\end{tabular}

RMAE of IDW for samples with benthic dredged samples (BD) is $28.49 \%$, an increase in predictive error by $1.79 \%$ in comparison with the RMAE of IDW of the QCed samples. The difference in RMAE between IDW for QCed and BD samples has a p-value of 0.0478. The higher predictive error of IDW for BD is significant.

RMAE of IDW for samples with chain bag type samples (CBD) is $26.23 \%$, a decrease in predictive error of $0.47 \%$ over the RMAE of IDW of the QCed samples. The difference in RMAE between IDW for QCed and CBD samples has a p-value of 0.0469 . The lower predictive error of IDW in the Southwest region for CBD is significant, but the effect is small as the difference in RMAE is $0.47 \%$. 
Dunn and Li, Assessment of the effects of the inclusion of poor quality sediment samples on spatial predictions of seabed sediments in the Australian marine margin

RMAE of IDW for samples with unspecified dredged samples (D-U) is $26.64 \%$. D-U have a lower predictive error of IDW than QCed samples. A Mann-Whitney test on IDW predictive errors for D-U gives a p-value of 0.1861 . The lower predictive error of IDW in the Southwest region for D- is not significant.

\subsection{Southwest region results $-\mathrm{OK}$}

RMAE of OK for the QCed samples in the Southwest region is $28.30 \%$ (Table 1). RMAE of OK for QCed samples with all the dredged samples (D-A) is $27.62 \%$. D-A has a lower predictive error of OK than the QCed samples. The Mann-Whitney test on OK predictive error for D-A gives a p-value of 0.0010 . The lower predictive error of OK for D-A is significant but the effect is small with a difference in RMAE of $0.68 \%$.

RMAE of OK for samples with benthic dredged samples (BD) is 32.61\% and RMAE of OK for QCed samples with pipe dredged samples (PD) is $29.53 \%$. Both BD and PD have higher predictive error of OK than QCed samples. Mann-Whitney tests on IDW predictive errors for BD and PD give p-values of 0.1624 and 0.3306 respectively (Table 1). The higher predictive error of OK for $\mathrm{BD}$ and $\mathrm{PD}$ is not significant. RMAE of OK for samples with chain bag type samples (CBD) is $27.05 \%$. The difference in RMAE of OK between CBD and QCed samples of $1.25 \%$ in the Southwest is not significant, with p-value of 0.8074 .

RMAE of OK for samples with unspecified dredged samples (D-U) is $27.65 \%$. D-U has lower predictive error of OK than QCed samples. A Mann-Whitney test on OK predictive errors for D-U gives a p-value of 0.0000 . The lower predictive error of OK D-U is significant but the effect is small as the RMAE difference is $0.65 \%$.

\subsection{Petrel region results - IDW}

RMAE of IDW for the QCed samples in the Petrel region is $49.76 \%$ (Table 2). RMAE of IDW for samples with all the dredged samples (D-A) is $46.73 \%$, RMAE of IDW for samples with pipe dredged samples (PD), is $48.82 \%$, and RMAE of IDW for samples with unspecified dredged samples (D-U) is $47.56 \%$. D-A, PD and D-U all have lower predictive error of IDW than the QCed samples. Mann-Whitney tests on IDW predictive errors for D-A, PD and D-U give p-values of 0.1696, 0.2077, and 0.9030. The lower predictive error of IDW for samples with D-A, PD and D-U is not significant.

Table 2. RMAE of IDW and OK for various sample types for the Petrel region and the differences (p-values) in the RMAE between QCed samples (without dredge) and samples with various dredged samples based on paired Mann-Whitney tests.

\begin{tabular}{|l|l|l|l|l|l|}
\hline \multirow{2}{*}{ Sample type } & \multicolumn{2}{|c|}{ IDW } & \multicolumn{2}{c|}{ OK } & \\
\cline { 2 - 6 } & RMAE (\%) & \multicolumn{1}{|c|}{ p-value } & \multicolumn{1}{c|}{ RMAE (\%) } & palue \\
\hline Without Dredge (QCed) & 49.76 & - & 47.79 & - & 237 \\
\hline Dredge - All (D-A) & 46.73 & 0.1696 & 45.79 & 0.1624 & 534 \\
\hline Pipe Dredge (PD) & 48.82 & 0.2077 & 47.81 & 0.0124 & 283 \\
\hline Dredge - Unspecified (D-U) & 47.56 & 0.9030 & 46.26 & 0.3306 & 488 \\
\hline
\end{tabular}

\subsection{Petrel region results - OK}

RMAE of OK for the QCed samples (without dredge) in the Petrel region is $47.79 \%$ (Table 2). RMAE of OK for samples with all the dredged samples (D-A) is $45.79 \%$. The lower predictive error of OK for samples with D-A samples is not significant as the Mann-Whitney test gives p-value 0.1624. RMAE of OK for samples with pipe dredge samples (PD) is $47.81 \%$. The Mann-Whitney test on OK predictive errors for PD gives p-value 0.0124 . The lower predictive error of OK for PD is significant with a very small effect on RMAE of $0.02 \%$. RMAE of OK for samples with dredge-unspecified samples (D-U) is $46.26 \%$. The lower predictive error of OK for D-U is not significant as the Mann-Whitney test gives p-value of 0.3306 .

\section{DISCUSSIONS AND CONCLUSIONS}

\subsection{Effects of the inclusion of dredged samples on the accuracy of spatial predictive models}

The difference in accuracy of IDW in the Southwest region for QCed samples and samples with dredged samples included was insignificant for the unspecified, all-dredged samples and pipe dredged samples. Including benthic type samples in the prediction reduced the accuracy of IDW in the Southwest region. Including chain bag type samples in the Southwest region increased the accuracy of IDW, but the effect is 
Dunn and Li, Assessment of the effects of the inclusion of poor quality sediment samples on spatial predictions of seabed sediments in the Australian marine margin

small. No significant effects on the accuracy of IDW in the Petrel region were found for samples including samples with all-dredged, unspecified and pipe dredged samples (all the tested dredged types).

The difference in accuracy of OK in the Southwest region for QCed samples and samples with dredged samples included was insignificant for samples with benthic dredged, pipe dredged and chain bag dredged samples. Including all-dredged or unspecified dredged samples increased the accuracy of OK in the Southwest region, but the effect is small for samples with all-dredged samples and with unspecified dredged samples. The difference in accuracy of OK in the Petrel Region for QCed samples and samples with all-dredged and with unspecified dredged samples was insignificant. Including samples with pipe dredged samples increased the accuracy of $\mathrm{OK}$ in the Petrel but the effect is marginal. We have demonstrated that the inclusion of dredged samples has little effect on the accuracy of IDW and OK spatial predictive models in these regions. Further tests using other spatial prediction methods are necessary to determine whether different dredge types have different effects on the accuracy of other spatial prediction methods.

\subsection{Effects of the inclusion of dredged samples on the accuracy of spatial predictions of different regions}

Three dredged sample types were tested in both the Southwest and Petrel Region; all dredged samples, unspecified dredged samples, and pipe dredged samples. We found no significant differences in accuracy between IDW of QCed samples and IDW of all dredged, unspecified dredged and pipe dredged samples in either the Southwest or Petrel regions, and therefore there is no difference in the effects of these dredge types on the predictive accuracy of IDW between both regions.

Samples with all-dredged samples and samples with unspecified dredged samples improved the accuracy of $\mathrm{OK}$ in the Southwest region, and samples with pipe dredged samples reduced the accuracy of OK in the Petrel region, but the effects of including these samples were very small. Accuracy of OK with all dredged and unspecified dredged samples in the Petrel region was improved, but this was not significant. Therefore, effects were not consistent across dredge types, but the improvement in the accuracy of OK is negligible. Further testing in other regions of the Australian marine margin is necessary to determine whether the effects are region-specific.

\subsection{Was the decision to exclude dredged samples valid?}

Testing for differences in the accuracy of spatial predictions of seabed sediment content created with and without including previously discarded samples is important, as samples were historically discarded on the basis of their quality. We expected to find large and significant improvement in the accuracy of spatial predictions of seabed mud content created with and without including the dredged samples. However, the largest difference in accuracy was an increase in predictive error in IDW predictions including benthic dredged samples in the Southwest region. As no large, significant increases in the accuracy of IDW or OK predictions of seabed mud content were found for predictions including dredged sample types in the Southwest and Petrel regions, we cannot provide evidence to change the decision to discard dredged samples.

\subsection{Can we improve future spatial predictions by including dredged samples?}

Inclusion of chain bag type samples improved the accuracy of the IDW predictions, and inclusion of alldredged or unspecified dredged samples improved the accuracy of the OK predictions in the Southwest region; and inclusion of pipe dredged samples improved the accuracy of the OK predictions in the Petrel region. However, these improvements are marginal with an effect size of $<0.7 \%$. Inclusion of samples of other dredge types did not improve the predictions of IDW and OK, that is, this study did not identify large changes to the accuracy of the spatial predictions of seabed mud content by including dredged samples.

It is surprising that the accuracy of the spatial predictive models was minimally affected by the inclusion of dredged samples. If further studies support these conclusions, it may be possible to use dredged samples to create spatial predictions in areas where dredged samples are the only available samples. The lack of consistent effects across regions, spatial prediction methods and dredge types in this study suggests that the effect of the dredge sample types on the accuracy of the spatial predictions depends on the dredge type and region. Because of this it is not possible to recommend the inclusion of samples of any dredge types for future spatial predictions in these study areas based on the data and findings in this study. We suggest that further testing needs to be undertaken to determine whether dredged samples should be included for different dredge types and spatial prediction methods in the other regions within the AEEZ. 
Dunn and Li, Assessment of the effects of the inclusion of poor quality sediment samples on spatial predictions of seabed sediments in the Australian marine margin

\section{ACKNOWLEDGEMENTS}

We would like to acknowledge Silvio Mezzomo for his assistance with map production and templates. We also thank Andrew Turner for his assistance with ArcGIS, IDW and OK techniques. This paper is published with the permission of the CEO, Geoscience Australia.

\section{REFERENCES}

Blomqvist, S. and Lundgren, L. (1996). A benthic sled for sampling soft bottoms. Helgoländer Meeresuntersuchungen 50(4), 453-456.

Brodie, J., Waterhouse, J., Schaffelke, B., Kroon, F., Thorburn, P., Rolfe, J., Johnson, J., Fabricius, K., Lewis, S., Devlin, M., Warne, M., Mckenzie, L., Shaw, R., Abal, E., Grundy, M., Doherty, P. and Byron, N. (2013). Reef water quality scientific consensus statement 2013. Queensland Government, Brisbane.

Dunn, B. and Li, J. (2018). Effects of poor quality samples on the accuracy of spatial predictions of seabed sediments. Geoscience Australia, Record 2018/xxx (in press).

ESRI (2013). ArcGIS ArcMap 10.2 Environmental Systems Research Institute (ESRI). 10.2.

Falkner, I., Heap, A., Przeslawski, R. and Whiteway, T. (2009). Review of Ten Key Ecological Features (KEFs) in the Northwest Marine Region : a report to the Department of the Environment, Water, Heritage and the Arts by Geoscience Australia. Geoscience Australia, Canberra.

Hailwood, E. A. and Kidd, R. (2012). Marine Geological Surveying and Sampling. Springer Netherlands.

Heap, A. D., Edwards, J., Fountain, L., Spinnocia, M., Hughes, M., Mathews, E., Griffin, J., Borissova, I., Blevin, J., Mitchell, C. and Krassay, A. (2008). Geomorphology, sedimentology and stratigraphy of submarine canyons on the SW Australian slope - post survey report. Geoscience Australia, Canberra. 2008/16, 138 pp.

Jiang, W. and Li, J. (2014). The effects of spatial reference systems on the predictive accuracy of spatial interpolation methods. Record 2014/01. Geoscience Australia, Canberra, pp 33.

Kidd, R., Huggett, Q. and Ramsay, A. (1990). The status of geological dredging techniques. Marine geophysical researches 12(1-2), 131-143.

Lark, R. M., Dove, D., Green, S. L., Richardson, A. E., Stewart, H. and Stevenson, A. (2012). Spatial prediction of seabed sediment texture classes by cokriging from a legacy database of point observations. Sedimentary Geology 281, 35-49.

Li, J. (2013). Predicting the spatial distribution of seabed gravel content using random forest, spatial interpolation methods and their hybrid methods. In: The International Congress on Modelling and Simulation (MODSIM) 2013, Adelaide. 394-400 pp.

Li, J. (2016). Assessing spatial predictive models in the environmental sciences: Accuracy measures, data variation and variance explained. Environmental Modelling \& Software 80, 1-8.

Li, J. (2017). Assessing the accuracy of predictive models for numerical data: Not $r$ nor $\mathrm{r}^{2}$, why not? Then what? PloS one 12(8), e0183250.

Li, J. and Heap, A. (2008). A Review of Spatial Interpolation Methods for Environmental Scientists. Geoscience Australia, Record 2008/23, 137pp.

Li, J., Heap, A., Potter, A. and Daniell, J. J. (2011). Predicting Seabed Mud Content across the Australian Margin II: Performance of Machine Learning Methods and Their Combination with Ordinary Kriging and Inverse Distance Squared. Geoscience Australia, Record 2011/07, 69pp.

Li, J., Potter, A., Huang, Z., Daniell, J. J. and Heap, A. (2010). Predicting Seabed Mud Content across the Australian Margin: Comparison of Statistical and Mathematical Techniques Using a Simulation Experiment. Geoscience Australia, 2010/11, 146pp.

Li, J., Potter, A., Huang, Z. and Heap, A. (2012). Predicting Seabed Sand Content across the Australian Margin Using Machine Learning and Geostatistical Methods. Geoscience Australia, Record 2012/48, 115pp.

Passlow, V. (2005). Final Report: National Marine Sediments Database and Seafloor characteristics project. Geoscience Australia.

Porter-Smith, R., Harris, P. T., Andersen, O. B., Coleman, R., Greenslade, D. and Jenkins, C. J. (2004). Classification of the Australian continental shelf based on predicted sediment threshold exceedance from tidal currents and swell waves. Marine Geology 211(1-2), 1- 20.

R Development Core Team (2016). R: A Language and Environment for Statistical Computing. R Foundation for Statistical Computing, Vienna, Austria.

Stephens, D. and Diesing, M. (2015). Towards Quantitative Spatial Models of Seabed Sediment Composition. PloS one 10(11), e0142502.

Turner, A. (2017). Effects of Spatial Reference Systems on the Accuracy of Spatial Predictive Modelling along a Latitudinal Gradient (in press). 